\title{
VIABILIDADE ECONÔMICA DA PRODUÇÃO DE CERVEJA ARTESANAL - BLACK BEER
}

ECONOMIC FEASIBILITY OF CRAFT BEER PRODUCTION - BLACK BEER

\author{
Cesar Renan Valencia Delascrea - cesarrenan2016@gmail.com \\ Faculdade de Tecnologia de Taquaritinga - Taquaritinga - São Paulo - Brasil \\ Marcela Midori Yada de Almeida - marcela.almeida@fatec.sp.gov.br \\ Faculdade de Tecnologia de Taquaritinga - Taquaritinga - São Paulo - Brasil
}

DOI: 10.31510/infa.v18i1.1147

Data de submissão: 16/04/2021

Data do aceite: $09 / 07 / 2021$

Data da publicação: 30/07/2021

\begin{abstract}
RESUMO
O presente artigo tem como objetivo, expor a potência que o mercado cervejeiro brasileiro tem perante as demais nações. Junto a isso, ele terá por finalidade demonstrar a tendência dos consumidores em relação a produtos provenientes de fórmulas caseiras, trazendo inovação, oportunidade de mercado e sabor diferenciado diante as concorrências. Com isso será apresentado uma ideia de negócio, que visa atender uma demanda expressiva dos apreciadores de cervejas artesanais. Foram inseridos e abordados todos os parâmetros que o mercado necessita e exige, desde análises financeira e marketing para se tornar viável aos olhos dos investidores e principalmente aos consumidores.
\end{abstract}

Palavras-chave: Viabilidade econômica, cerveja artesanal

\begin{abstract}
This article aims to expose the power that the brazilian beer marketing has to Other nations. Along with this, it will aim to demonstrate the trend of consumers in relation to products from homemade formulas, bringing innovation, markentig opportunity and differentiated flavor in the face of competion. With this, a business idea will be presented, which aims to meet an expressive demand from craft beer lovers, were inserted and addressed all parameters that the market needs and requires, from financial analysis and marketing to become viable in the eyes of inventors and especially consumers.
\end{abstract}

Keywords: Economic viability, craft beer. 


\section{INTRODUÇÃO}

\section{INTERFACETECNOLÓGICA}

O mercado brasileiro de cerveja tem ganhado destaque na última década, se fixando entre os quatro maiores do mundo juntamente com a China, Estados Unidos e Alemanha. A cerveja Pilsen é líder absoluta de preferência, $98 \%$ do total consumido. A tendência do mercado cervejeiro brasileiro é a segmentação, pois consumidores estão mais interessados em experimentar produtos diferenciados (PINTO et al., 2015).

As cervejas artesanais cada vez mais vem conquistando mercado, atualmente muitas são as bases que reservam espaços específicos para este tipo de cerveja para quem gosta de apreciar novos e exclusivos sabores da bebida (LARA, 2018). Para Pinto et al. (2015), o crescimento do número de micro cervejarias brasileiras é pequeno e o mercado está se desenvolvendo. Entretanto, a falta de equipamentos de boa qualidade voltadas para a pequena escala, a carga tributária excessiva, burocracia dos órgãos fiscalizadores, a legislação ultrapassada, a dificuldade na aquisição das matérias - primas e, principalmente a preferência do consumidor, tornam - se entraveis para o desenvolvimento desse novo setor.

Hoje, no Brasil, a maioria das cervejas que são feitas com um processo especial e mais cuidadoso, na prática, acabam sendo chamadas de cerveja artesanais, o correto seria chamar de cervejas especiais (LARA, 2018). Segundo Tozeto (2017), as cervejas artesanais dizem respeito a uma classe de produtos com qualidade superior e mais valor agregado, produzidas por meio de formulações de processos distintos utilizados em escala industrial. A produção em pequena escala possibilita produtos diferenciados aos consumidores, mais exigentes com os cuidados da seleção da matéria prima e levando a uma tendência de valorização do regional. E para Lara (2018), as cervejas artesanais advém de um processo artesanal mais cuidadoso em sua produção, enquanto as cervejas industrializadas têm por objetivo a produção em grande escala com grandes maquinários.

O objetivo do trabalho é apresentar o mercado de cerveja artesanal voltado para produtores iniciantes, analisando a viabilidade de concretização do negócio, com os investimentos necessários, alocação de recursos e mitigação de curto a médio prazo. 


\section{WNERPAGE TECNOLÓGicA}

\section{FUNDAMENTAÇÃO TEÓRICA}

\subsection{ANÁLISE DE MERCADO}

A atuação do mercado de cerveja artesanal é grande e tem apresentado um crescimento nos últimos anos no Brasil. De acordo com Claumann et al. (2018), o interesse pelas marcas artesanais começou a crescer recentemente, o brasileiro sempre teve um grande interesse por cerveja, entretanto não muito por cervejas artesanais e produzidas no país, em 2007, o Brasil se encontrava entre os 10 maiores consumidores no mundo, dez anos depois, em 2017, o país subiu para a terceira posição (CLAUMANN et al., 2018).

No mundo todo, existem cerca de 19 mil cervejarias, de acordo com a pesquisa divulgada pela Alltech e The Brewers Journal em 2017. Desse número, 94\% são produtores artesanais e, no ranking dos 5 maiores produtores de cerveja artesanal estão Estados Unidos, Reino Unido, Alemanha, Itália e Espanha (CLAUMANN et al., 2018).

Mesmo que o Brasil não ocupe o ranking dos 5 maiores produtores de cerveja artesanal do mundo, o cenário interno tem crescido e muito, aumentando a competitividade interna, tornando mercado ainda mais disputado. Já que não foi só o consumo quem cresceu nos últimos ano, o paladar do brasileiro também se alterou: o número de cervejarias artesanais cresceu 91\% entre 2015 e 2017, com 186 novas marcas somente nesse último ano, para o ramo no ano 2017, o país contou com 679 estabelecimentos registrados, sendo mais de $80 \%$ deles localizados nas regiões Sul e Sudeste (CLAUMANN et al., 2018).

No mercado interno, os estados que mais produzem são Sul com 42,27\% seguido do Sudeste com a porcentagem de 41,09\%, região onde nossa empresa estará localizada e produzirá. No ano de 2016, a Associação Brasileira da Indústria da Cerveja (CervBrasil) gerou cerca R \$ 27 bilhões em impostos e R \$ 23 bilhões em salários. Em 2017, segundo Claumann et al. (2018), o faturamento foi de R $\$ 170$ bilhões, e os investimentos no setor entre 2014 e 2017 somaram R \$ 12 bilhões. Para cada R \$ 1,00 investido, estima-se que são gerados outros R \$2,50, dados estes que demonstram o quanto cresceu o mercado interno de cerveja artesanal.

Local temos concorrente brewpubs como a Blessed Hop Cervejas Especiais que recentemente estreou no mercado matonense, a primeira cerveja artesanal produzida por eles (BE BLESSED) uma Juicy Ipa a um preço de $\mathrm{R} \$ 20,00$ cada. E estabelecimentos distribuidores de cervejas artesanais com preços competitivos, mas com abertura para que possamos divulgar a nossa marca através deles. 


\section{|WTERPAGETECHOĹGicA}

De acordo com Carlo Lapolli (Presidente da Associação Brasileira de Cerveja Artesanal), o Brasil em 10 anos foi de 70 a 700 cervejarias um crescimento de $35 \%$ entre os anos de 2016 e 2017. Com o impulsionamentos de produtos gourmet, no presente ano esse número pode ter sido alancado ainda mais, pois a tendência por novos sabores e inovação tem aumentado a procura por produtos dessa escala.

Bressiani, diretor da escola Cerveja e Malte, aponta que as mulheres também foram grandes influenciadoras para o desenvolvimento das cervejas, onde nos últimos elas têm migrado para este tipo de consumo o que facilitou no processo de criação.

A Plataforma e-commerce Clube do Malte realizou um estudo sobre o comportamento e os hábitos de consumo de cerveja no Brasil, e de acordo com o relatório "Comportamento Cervejeiro Brasileiro: Uma Pesquisa sobre Hábitos de Consumo no País”, entre outras coisas, definiu o perfil socioeconômico do apreciador da bebida: a maior parte é composta por homens entre 31 e 40 anos, casados, sem filhos, com nível superior completo ou pós-graduação, e renda mensal entre R\$ 3 mil e R\$ 6 mil (MEZZADRI, 2018)

Essa informação pode ser confirmada através de uma Publicação do Site Cerveja e Malte, onde segundo a pesquisa feita por startup Mind Miners, mostra que homens de classe alta e com idades entre 25 a 40 anos são os principais consumidores de rótulos artesanais. Já o consumo entre os mais jovens na faixa de 18 a 24 anos apenas $28 \%$ dos consumidores dizem beber cervejas artesanais em casa, contra uma média de 51\% nas demais faixas etárias. Entre este público está ainda os que informaram consumi-las com menos frequência em quaisquer lugares, sejam restaurantes, bares, baladas e outros eventos sociais (CERVEJA E MALTE, 2019).

\subsection{Legislação}

Segundo a descrição contida no site do Governo Federal (2020), a Legislação Brasileira sobre bebidas é dividida em dois segmentos: as normas referentes ao vinho e derivados de uva e as normas relativas as demais bebidas. De acordo com o Governo Federal (2020), as bebidas são registradas pela Lei n 8.918 . de 14 de julho de 1994, regulamentadas pelo Decreto n6.871, de 04 de junho de 2009. Além disso, os aditivos e os coadjuvantes de tecnologia permitidos em cada bebida estão definidos em legislação específica da Agência Nacional de Vigilância Sanitária (ANVISA), com disposições estabelecidas em normas e decretos do Ministério da Agricultura, Pecuária e Abastecimento (MAPA). 


\section{WTERPAGE TECNOLÓGICA}

De acordo com a atual legislação brasileira para bebidas alcoólicas não há regras para cerveja artesanal, apenas para cerveja industrializada.

\section{PROCEDIMENTOS METODOLÓGICOS}

\subsection{Dimensionamento, localização e estrutura}

A escolha da localização dentro do projeto foi no intuito de haver maior viabilidade e melhor aproveitamento em todos os quesitos. A empresa será desenvolvida dentro da cidade de Matão-SP, mais precisamente no Parque Industrial Toriba, onde para o início e desenvolvimento da cervejaria se apresenta mais adequado.

A escolha pelo parque foi pelo fato de ter um espaço amplo, para receber fornecedores através de veículos pesados e conseguir ter maior mobilidade no local. E pela questão das instalações, onde comporta ter equipamentos que não tragam riscos aos cidadãos da área urbana. Já a escolha da cidade foi através de questões estratégicas para escoamento e consumo do produto. Matão é uma cidade em constante crescimento e consequentemente tem uma renda populacional significativa, onde com isso conseguiria atingir um maior número de pessoas com poder aquisitivo para apreciar uma cerveja com preço agregado no mercado. E por haver bares noturnos espalhados pela cidade, onde facilitaria o contato da cerveja com consumidores primários, ajudando a ter uma análise e realizar constantes melhorias no desenvolvimento do produto.

\subsubsection{Capacidade Produtiva e Layout}

Por estar adentrando no ramo de cervejas artesanais e por ter pouca experiência no mercado deste produto, a meta inicial é de 8.000 litros mensais e através da demanda recebida e o amadurecimento e crescimento no mercado de cervejas artesanais a produção crescerá.

A área inicial de $1.000 \mathrm{~m}^{2}$ onde está dimensionada cinco recintos, contendo a recepção, loja física, fabricação, estoque e escritório (Figura 1). Contudo há a possibilidade de se aumentar as instalações de fabricação e do conforme houve aumento da demanda. 


\section{WWTEREACEETECWOLÓGICA}

Figura 1. Layout da planta de produção.

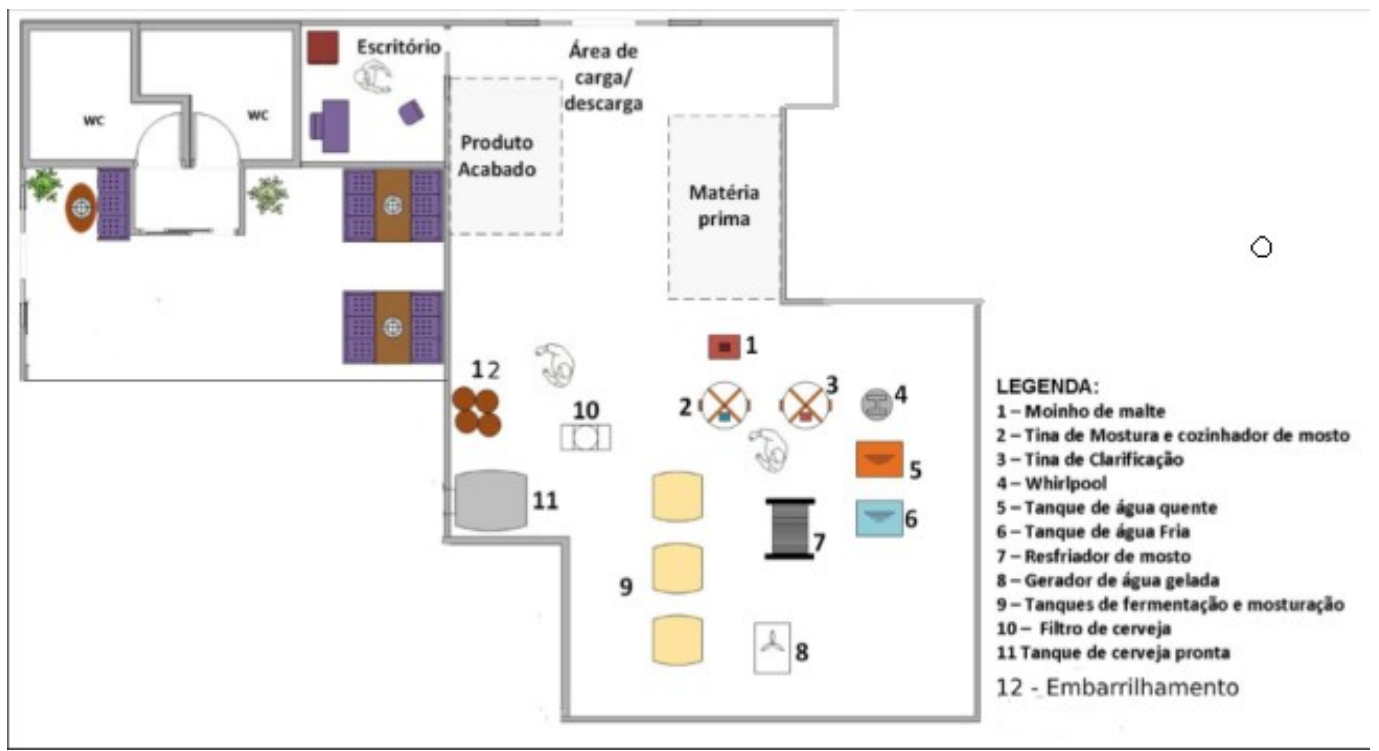

Fonte: Os autores (2021)

Escolheu-se este arranjo produtivo para se trata de uma empresa de pequena com suas instalações adequadas para a ocasião.

\subsubsection{Distribuição e Venda}

A cervejaria irá utilizar o formato de venda no qual não se mantém contato direto com o consumidor final, e para iniciantes e empresas de pequeno a médio porte, é o mais utilizado. Através do método B2B no qual duas empresas fazem negócios como cliente e fornecedor, outra maneira de atuar no mercado é através da plataforma de e-commerce B2B criada pela Fast Channel para ajudar o produtor de cerveja artesanal a utilizar a internet como uma poderosa ferramenta de vendas.

Dentro deste método de negociação, o tempo até a venda de uma solução é maior, o processo é mais complexo, mas uma vez que ocorre torna-se mais estável. Por outro lado, o número de clientes é menor, exige-se que o serviço seja qualificado e que os próprios clientes sejam propagadores da marca. Por outro lado, o tamanho da venda é maior, porque empresas costumam fazer compras maiores, com mais frequência e por um período maior. 


\section{INTERFACETECNOLÓGICA}

\subsubsection{Análise financeira}

A análise financeira do projeto de Cerveja Artesanal terá como base a busca por investimento, o quanto de custos e de despesas o projeto terá, além de estipular um preço de venda e quais serão as receitas.

Para ver se há retorno financeiro será avaliado o fluxo de caixa e a taxa de desconto, o valor Presente Líquido (VPL) e a Taxa Interna de Retorno (TIR) para o estudo de caso. Para o Capital Research (2020), payback simples é um indicador financeiro que revela o tempo necessário para recuperar o custo de um investimento, ou seja, equivale ao prazo de retorno do investimento, ou quanto tempo ele leva para se pagar. E, para Reis (2019), o payback descontado é o tempo de recuperação do investimento descontado do fluxo de caixa.

Para Camargo (2017), o valor presente líquido (VPL), também chamado de valor líquido atual, o VPL, é um método que consiste em trazer para a data zero fluxo de caixa de um projeto de investimentos e somá-los ao valor de investimento inicial, usando como taxa de desconto a taxa mínima de atratividade (TMA) da empresa ou projeto. Por fim, segundo Camargo (2017), a taxa interna de retorno (TIR) é a taxa que irá igualar o fluxo de caixa antecipado para o valor de investimento.

\section{RESULTADOS E DISCUSSÕES}

\subsection{Plano de marketing}

O mercado cervejeiro para bebidas independentes, têm-se mostrado propício no interior das grandes capitais brasileiras, buscando explorar as microrregiões para obter maior abertura de mercado e baixa concorrência, na qual é possível construir parcerias duradouras através de vendas B2B. Diante desta constatação, será analisado a quantidade de estabelecimentos nas cidades de Matão e Araraquara com interesse em oferecer um menu diversificado aos clientes, para divulgação de novas marcas cervejeiras independentes. E para alavancar os resultados da Black Beer, apresenta-se o plano de Marketing:

Produto - Receitas especiais diversas de cervejas artesanais com sabores incomuns e atrativos ao paladar. Nossas Cervejas provenientes de Sabores Cítricos será a Black Bitter. Vamos ter também a Black Juice que vai trazer suavidade através de trigo belga e com a presença da casca da Laranja dará muito mais sabor. E por fim terá a Black Pilsen onde apresentará notas maltadas de biscoitos e cereais, se tornando uma bebida mais leve. 


\section{NTIERPACE TECNOLÓGICA}

Praça - Atuará de forma seletiva no mercado, através do modelo de vendas $\mathrm{B} 2 \mathrm{~B}$, atendemos o cliente final, através do fornecimento dos produtos para restaurantes, bares, casas noturnas, empório de bebidas e entre outros estabelecimentos.

Preço - Variável conforme a embalagem e o volume de compra de cada cliente. Preço fixo apenas para acordo de 12 a 24 meses, passível de reajuste, de acordo a variação do mercado para os itens base, utilizados na confecção das cervejas.

Promoções - Para desenvolver rapidamente a base de clientes, será feito uma network com a degustação das cervejas, bem como promoções de compras para os potenciais clientes. Será enviado um barril de 5 litros com a principal receita de inauguração no mercado como uma oportunidade de o cliente em potencial conhecer o produto e testá-lo com o seu consumidor. Será criado um site de vendas, na qual será possível recolher encomendas de todas as regiões do interior de São Paulo.

Degustação - Quinzenalmente, será promovida aos clientes a oportunidade de conhecer o processo produtivo e degustar das s cervejas. A degustação servirá para atrair clientes e demonstrar a qualidade e o cuidado envolvidos no processo produtivo.

Vendas - Com uma estimativa conservadora, a cervejaria produzirá, em média, em um dia útil, 10 mil litros, elaborados em um preço médio de R\$12,00 o litro, está incluso neste valor, o custo dos equipamentos, mão de obra do mestre cervejeiro, custos de produção. Portanto, a fábrica venderá, em média, em um dia útil, $R \$ 120.000,00$ reais. Considerando 20 dias uteis no mês, a venda mensal será de $\mathrm{R} \$ 2.400 .000,00$ reais.

\subsection{Análise Financeira}

De acordo com as análises realizadas dentro das perspectivas do mercado cervejeiro, existe espaço para trazer algo inovador, com valor agregado e que conquiste um público próprio para o produto ofertado. Para que a proposta tenha formato, foi listado equipamentos que farão parte do processo produtivo e que será essencial para a indústria (Tabela 1). Através disso teve acesso aos custos necessários para investimento diretamente e indiretamente na produção da cerveja (Tabela 2 e 3). Após essa análise torna ainda mais atrativo o negócio e abre oportunidades para visar o retorno de capital desejado (Tabela 4).

Quanto à análise dos indicadores de viabilidade econômica (Tabela 5), observou-se que o TIR, VPL e Payback foram atingidos de forma representativa com valores superiores ao que o mercado entende como necessário para o bom funcionamento e rendimento econômico da 


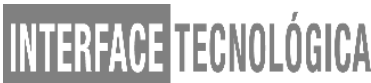

empresa. Houve também a verificação do período em que a empresa terá o seu capital recuperado em função do fluxo de caixa, com índices satisfatórios de corrente ao investimento inicial.

Tabela 1. Itens necessários para Fabricação da Cerveja

\begin{tabular}{|c|c|c|c|c|}
\hline \multicolumn{5}{|c|}{ EQUIPAMENTOS / UTENSILIOS / ACESSÓRIOS } \\
\hline Item & Quant & Descriçao & Valor Unit & Valor total \\
\hline 5 & 3 & Registros Completos 1/4 PP & 60,00 & 180,00 \\
\hline 6 & 3 & Fogareiro 14 Caulins Sem Borda & 250,00 & 750,00 \\
\hline 7 & 3 & Bomba Circulação & 290,00 & 870,00 \\
\hline 8 & 5 & 2 Metros de Silicone Atoxica 10x14 (3/8) & 32,00 & 160,00 \\
\hline 9 & 2 & Abraçadeiras & 20,00 & 40,00 \\
\hline 10 & 2 & Baldes Fermentadores 22L & 95,00 & 190,00 \\
\hline 11 & 1 & Bonbona Fermentadora 50L & 190,00 & 190,00 \\
\hline 12 & 3 & Airlock Tipo S & 20,00 & 60,00 \\
\hline 13 & 2 & Torneira Simples & 60,00 & 120,00 \\
\hline 14 & 2 & Torneira com redutor de Sedimentos & 30,00 & 60,00 \\
\hline 15 & 3 & Balança Digital 0KG A 10KG & 35,00 & 105,00 \\
\hline 16 & 10 & Densimetros 1000-1100 & 55,00 & 550,00 \\
\hline 17 & 10 & Proveta $250 \mathrm{ml}$ LABSYNTH & 11,80 & 118,00 \\
\hline 18 & 5 & Termometro Cervejeiro & 56,99 & 284,95 \\
\hline 19 & 5 & Termomentro Espeto Digital & 86,02 & 430,10 \\
\hline 20 & 500 & Chiller em Aluminio de $3 / 8$ & 4,66 & $2.330,00$ \\
\hline 21 & 3 & Arrolhador Italiano C/ Bocal Extra+ 300 Tampas Pry Off & 265,90 & 797,70 \\
\hline 22 & 10 & Escova $\mathrm{N}^{\circ} 14$ & 20,00 & 200,00 \\
\hline 23 & 10 & Escova $\mathrm{N}^{\circ} 15$ & 40,00 & 400,00 \\
\hline 24 & 10 & Escova $\mathrm{N}^{\circ} 7$ & 18,00 & 180,00 \\
\hline 25 & 40 & Alcool 1L & 7,00 & 280,00 \\
\hline 26 & 1 & Frasco lodofor $50 \mathrm{ml}$ & 20,00 & 20,00 \\
\hline 27 & 100 & Kit 100 Frasco Pulverizador / Borrifador $500 \mathrm{ml} \mathrm{C/4}$ & 4,94 & 493,85 \\
\hline 28 & 5 & Placa de Toque 3 Cavidades & 12,57 & 62,85 \\
\hline 29 & 5 & Peneira Cônica com Funil de $16 \mathrm{~cm}$ & 40,00 & 200,00 \\
\hline 32 & 5 & Valvula de encher Garrafas com Sensor $3 / 8$ & 394,90 & $1.974,50$ \\
\hline 33 & 500 & Pipeta Pasteur 3ml LABSYNTH & 0,09 & 43,86 \\
\hline 34 & 5 & KIT Erlenmeyer Vidro $1000 \mathrm{ml}$ LABSYNTH & 230,00 & $1.150,00$ \\
\hline 35 & 3 & Moedor, Moinho Malte Motorizado Com 2 Rolos E Funil Em Inox & $2.490,00$ & $7.470,00$ \\
\hline \multirow[t]{3}{*}{36} & 1 & Cozinha Ou Sala De Brassagem 400 Litros - Fabricação Cervej & $82.695,00$ & $82.695,00$ \\
\hline & & SUBTOTAL 2 & & $\mathrm{R} \$ 102.405,81$ \\
\hline & & TOTAL INVESTIMENTOS & & $\mathrm{R} \$ 102.405,81$ \\
\hline
\end{tabular}

Tabela 2. Custos Fixos da Cervejaria.

\begin{tabular}{|c|c|c|c|}
\hline \multicolumn{4}{|c|}{ CUSTOS FIXOS } \\
\hline Item & Descriçao & Valor/mês & Valor/ano \\
\hline 1 & Energia Eletrica & $4.000,00$ & $48.000,00$ \\
\hline 2 & Mão de Obra & $15.000,00$ & $180.000,00$ \\
\hline 3 & Seguro & 50,25 & 603,00 \\
\hline 4 & Manutenção & 800,00 & $9.600,00$ \\
\hline 5 & Depreciação & 25,27 & 303,24 \\
\hline 6 & Aluguél $1.100 \mathrm{~m} 2$ & $15.730,00$ & $188.760,00$ \\
\hline 7 & Escritorio & 350,00 & $4.200,00$ \\
\hline \multirow[t]{2}{*}{8} & Água & $4.000,00$ & $48.000,00$ \\
\hline & TOTAL & $R \$ 39.955,52$ & $R \$ 479.466,24$ \\
\hline
\end{tabular}




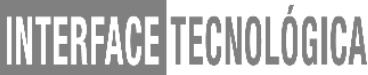

Tabela 3. Custos Variáveis da Cervejaria.

\begin{tabular}{|c|c|c|c|c|c|}
\hline \multicolumn{6}{|c|}{ CUSTOS VARÍÁVEIS } \\
\hline Item & Descriçao & Qtdade / mês & Valor unit. & Valor Total / mês & Valor Total / ano \\
\hline 1 & Tampinhas de Garrafas PRY-OFF & 8.000 & 0,10 & 800,00 & $9.600,00$ \\
\hline 2 & Frascos de 1L & $8.000,00$ & 2,00 & $16.000,00$ & $192.000,00$ \\
\hline 4 & Lupulo (KG) & 11,2 & 150,00 & $1.680,00$ & $20.160,00$ \\
\hline 5 & Agua (L) & 7.200 & 0,30 & $2.160,00$ & $25.920,00$ \\
\hline 6 & Levedura (KG) & 4,4 & 21,30 & 93,72 & $1.124,64$ \\
\hline 7 & Malte (KG) & 1.600 & 6,60 & $10.560,00$ & $126.720,0 \mathrm{C}$ \\
\hline & & TOTAL & & $\mathrm{R} \$ \mathbf{3 1 . 2 9 3 , 7 2}$ & $\mathrm{R} \$ \mathbf{3 7 5 . 5 2 4 , 6 4}$ \\
\hline
\end{tabular}

Tabela 4. Quantidade estimada dívidas por períodos.

\begin{tabular}{|c|c|c|c|c|c|}
\hline \multicolumn{6}{|c|}{ ESTIMATIVA DE PRODUÇÃO / RECEITA } \\
\hline Item & Descriçao / item & Qtdade / mês & Preço de venda & Receita Mensal & Receita anual \\
\hline 1 & Cerveja Artesanal (Principal Produto) - Litros & 8.000 & 10,00 & $80.000,00$ & $960.000,00$ \\
\hline 2 & Venda de Residuos Industriais (Kg) & 1.200 & 5,50 & $6.600,00$ & $79.200,00$ \\
\hline \multirow[t]{4}{*}{3} & & & & 0,00 & 0,00 \\
\hline & & & & & \\
\hline & & & & $\mathrm{R} \$ 86.600,00$ & $\mathrm{R} \$ \mathbf{1 . 0 3 9 . 2 0 0 , 0 0}$ \\
\hline & & & RECEITA LÍQUIDA & $\mathrm{R} \$ 15.350,76$ & $\mathrm{R} \$ 184.209,12$ \\
\hline
\end{tabular}

Tabela 5. Viabilidade econômica através da TIR (Taxa Interna de Retorno)

\begin{tabular}{|c|c|c|}
\hline $\begin{array}{l}\text { PAYBACK SIMPLES } \\
\text { PAYBACK DESC. }\end{array}$ & 0,56 & \\
\hline VPL & $\mathrm{R} S \mathbf{1 . 3 2 0 . 0 0 8 , 1 9}$ & \\
\hline TIR & $167 \%$ & \\
\hline \multicolumn{2}{|l|}{ Investimento total } & $102.405,81$ \\
\hline \multicolumn{2}{|c|}{ Custos fixos totais / período } & $479.466,24$ \\
\hline \multicolumn{2}{|c|}{ Custos variáveis totais / período } & $375.524,64$ \\
\hline \multicolumn{2}{|c|}{ Receita líquida total / período } & $184.209,12$ \\
\hline
\end{tabular}

\section{CONCLUSÃO}

Com todos os estudos em relação ao mercado cervejeiro, o mercado de cerveja artesanal é viável e bom para se investir, mesmo que esteja crescendo bastante nos últimos anos e se tenha uma concorrência em abundância é um mercado que possuí variáveis gostos e estilos de consumidores.

Considerando os dados apresentados, a fabricação de cervejaria artesanal possui valor expressivo para fabricantes iniciantes, porém com o mapeamento dos investimentos necessários para execução do business e elaborações de estratégias bem definidas considerando o share do mercado e a atuação da empresa, é possível torná-lo rentável e atrativo aos investidores. 


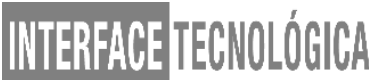

Obviamente, o desempenho e a viabilidade do negócio, está conectado diretamente com os custos de produção e a aceitação dos produtos pelos consumidores diretos e indiretos.

Dentro do que foi imaginado para a finalidade do estudo, nosso objetivo foi atingido tendo em vista todas as pesquisas e análises que foram trazidas para dentro do presente projeto, desde quesitos financeiros, estratégicos e da viabilidade em se ter uma empresa no ramo de cerveja artesanais.

\section{REFERÊNCIAS BIBLIOGRÁFICAS}

BODAS, A. Cerveja artesanal tem mercado quente para empreender e carreiras em alta. Publicado em VOCÊ/SA. Empreendedorismo. Disponível em:

$<$ https://vocesa.abril.com.br/empreendedorismo/mercado-de-cervejas-artesanais/> Acesso em 30 de setembro de 2020 .

B2B: vantagens e desvantagens do modelo de negócio 08/05/2019- Acesso em: 04 nov. 2021.

CAMARGO; R.F., Veja como valor presente líquido (VPL) ajuda na análise de viabilidade de um investimento. Disponível em:

www.google.com/amp/s/www.treaze.com.br/blog/valor-presente-liquido-vpl/amp Acesso em: $13 / 11 / 2020$.

CAMARGO; R.F., Taxa Interna de Retorno como o TIR é aplicado na análise de investimento de um projeto? Disponível em:

www.google.com/amp/s/www.treaze.com.br/blog/taxa-interna-de-retorno-tir/amp/> Acesso em: 13/11/2020

CLAUMANN, D. A., ALVES, O. A.; O mercado de cervejas artesanais Cenários 20182020 no Brasil e em Santa Cata. Disponível em:

$<$ http://simmmebnegocios.com.br/images/simmmebnegocios.com.br/noticias/OMercadoDeCe rvejasArtesanais.pdf Acesso em: 29/09/2020.

COPAGAZ. Conheça os equipamentos indispensáveis para produzir a sua cerveja artesanal. Publicado em 01 de outubro de 2019. Disponível em:

$<$ https://copagaz.com.br/conheca-os-equipamentos-indispensaveis-para-produzir-a-suacerveja-artesanal/. Acesso em 21 de outubro de 2020.

HOMINILUPULO; Cerveja Artesanal: tudo o que você precisa saberá respeito. Disponível em: $<$ https://www.hominilupulo.com.br/cervejas-caseiras/artigos/cerveja-artesanal $>$ Acesso em: $26 / 09 / 2020$

KROHN, L.V. BEBER, FAZER, VENDER: formação do mercado de cerveja "artesanal" no Brasil; Publicado: Universidade De São Paulo, Faculdade De Filosofia, Letras E Ciências Humanas. - 2018 São Paulo 


\section{INTERFACE TEENOLÓGICA}

$<$ https://forbes.com.br/negocios/2018/05/pesquisa-aponta-quem-mais-bebe-cerveja-artesanalno-brasil/

KWAKITA, L. H.; QUEIROZ, M.O.; Produção de Cerveja Artesanal em uma cidade do interior do Mato Grosso do Sul: um estudo de caso para implementação em Parnaíba - MS. I Simpósio Sul - Mato Grossense de Administração.

LARA, C. LAPOLI, C. Mercado da Cerveja 2018. Disponível em:

$<$ https://abracerva.com.br/rascunho-automático/>. Acesso em 30 de setembro de 2020.

PAYBACK Simples: O que é e como calcular. Disponível em:

www.capitalresearsh.com.br/blog/investimentos/payback-simples/

PINTO, L. I. F., ZAMBELLI, R. A., JUNIOR, E. C. S.; FONES, D. F., Desenvolvimento de Cerveja Artesanal com Acerola, (Malpighica emargenata DC) e abacaxi (Aramus Comsus L.Morril). Revista Verde. Pombel/PB. Vol.10. nº4. P.67 - 71. (2015)

REIS, T. Payback Descontado: saiba como funciona esse indicador de retorno. Disponível em: www.google.com/amp/s/www.sumaresearch.com.br/artigos/paybackdescontado/amp/

SPIESS, S. Plataforma de e-commerce para Cervejarias - 14 de agosto de 2018 Acessado em: https://www.ocaneco.com.br/plataforma-de-e-commerce-para-cervejarias/ 04/11/2020

TOZETO, L. M. Produção e caracterização de cerveja artesanal adicionada de gengibre (Zeniber afficinale). Dissertação - Tese de Mestrado. Universidade Tecnológica do Paraná, Programa de Pós-graduação em Engenharia de Produção. Ponta Grossa 2017. 